\title{
The development of $\mathrm{OE} \overline{\boldsymbol{e}}$ : Middle English spelling evidence Gjertrud F. Stenbrenden, University of Oslo
}

\section{Introduction}

The available evidence for Middle English (ME) long-vowel changes, including the so-called 'great vowel shift' (GVS), is scattered, both temporally and geographically, and notoriously difficult to interpret. ${ }^{1}$ The problems are arguably most serious for $\mathrm{OE} \bar{\alpha}$, whose phonetic correspondences and orthographic representations vary considerably even in Old English (OE). OE has $\bar{\alpha}$ from two main sources, as outlined below.

1. $\bar{e}^{1}$ from WGmc $a i+i$ is generally retained in all OE dialects except Kentish (Sievers 1968: $\S \S 57,62,90$; Campbell 1959: $\$ 197)$, and it may have been raised before dentals in parts of the country (Luick 1914-40: $\S 187-8$; Jordan 1925: §48, Anm.2).

2. $\bar{e}^{2}$ from WGmc $\bar{a}$ is retained in Saxon dialects, but is reflected as $\bar{e}$ in Anglian and Kentish (Wright \& Wright 1925: §119; Sievers 1968: §57; Campbell 1959: §257; Hogg 2011: $\S \S 3.22-3.25)$. In the East Saxon dialects, $\bar{e}^{2}$ is believed to have retracted to [a:] (Kristensson 1997).

When use of $\langle\mathfrak{x}\rangle,\langle\mathrm{ae}\rangle$, etc. is gradually discontinued after the Norman Conquest, matters only get worse, as the reflexes of both $\bar{e}$ 's come to be spelt $\langle\mathrm{e}(\mathrm{e})\rangle$, as indeed are reflexes of OE $\bar{e}$. Another complicating factor is the merger of the reflex of OE $\bar{e} a$ with that of $\bar{x}$, at which both were raised to 'long open $e$ ', possibly in the early eleventh century (Wright \& Wright 1928: $\S 63)$. Thus, the digraph <ea $>$ was also available as an orthographic device to indicate a long front vowel in the open or open-mid area. The orthographic result is a number of co-variants for what one might call 'eME $\bar{x}$ ', i.e. $\langle$ ea $\rangle,\langle$ ae $\rangle,\langle$ ee $\rangle$, besides traditional $\langle æ\rangle$, which, according to Wright \& Wright (1928: §52), was 'preserved in writing until about the end of the twelfth century, and occasionally even later’ (cf. Wyld 1914: §161).

The reflex of OE $\bar{\alpha}$ was raised to /e:/, thence to /i:/, in the GVS, but the raising process to [ع:] started earlier (Wyld 1914: $\S \S 120,161 ;{ }^{2}$ Campbell 1959: §292; Lutz 2004; despite Wright \& Wright 1928: §52). The terminal value [i:] is in evidence from the sixteenth century, according to Zachrisson (1913: 204) and Dobson (1968: 610). While this is likely true of the ancestor of $\mathrm{RP}$ and many other dialects, a distinction between the reflexes of OE $\bar{e}$ and OE $\bar{e}$ is upheld by some dialects into the 20th and 21th centuries (cf. Anderson 2015: sections 3.18-3.31). Nonetheless, forms with $\langle\mathrm{i}\rangle$ and $\langle\mathrm{y}\rangle$ in ME sources probably indicate early vowel shift of both $\bar{e}$ 's, even with the above caveat in mind.

This paper attempts, first, to present the range of spellings for the reflexes of the two $\bar{e}$ 's in ME dialects, as found in the Corpus of Tagged Texts for A Linguistic Atlas of Early Middle English ( $L A E M E$; see section 2). As my paper aims to show the totality of spellings for $\bar{e}^{1}$ and $\bar{e}^{2}$ in all the $L A E M E$ texts, it has not been possible to submit all individual scribal systems to detailed analysis (either in terms of co-variants or statistical significance), except in a few cases for illustration. Second, this article aims to establish the course of change, phonetically as well as orthographically, for the two $\bar{e}$ 's, and to determine the isoglosses for OE $\bar{e}^{2}$; that is, which ME

\footnotetext{
${ }^{1}$ I wish to thank the two anonymous reviewers, the editors, and members of the audience at the 1 st AMC Symposium for very useful commens and suggestions, for which this paper is much the better. All the remaining shortcomings are my own responsibility.

${ }^{2}$ Note that Wyld uses ' $\overline{e^{l}}$ ' to refer to the reflex of $\mathrm{W}$ Gmc $\bar{a}(\operatorname{PrOE} \bar{\alpha})$ and ' $\bar{c}^{2}$ ' to refer to the reflex of the $i$ mutated product of $\mathrm{W}$ Gmc ai.
} 
areas likely had [e:] and which had [æ:] for $\bar{e}^{2}$. Establishing the isoglosses for $\bar{e}^{2}$ is important in that it bears on the phonetic interpretation of the spellings thereof. Traditionally, forms with a shortened vowel have been used to determine the quality of the reflexes of $\bar{e}^{2}$ in ME, since the reflexes of both long vowels are spelt $\langle e(e)\rangle$ in ME: If the shortened reflex is spelled $\langle a\rangle$, it presumably goes back to [æ:], whereas if the shortened reflex is spelled $\langle\mathrm{e}\rangle$, it is supposed to go back to [e:]. Shortened forms are, however, infrequent in the main source of ME used here (LAEME), so such forms have not been exploited or analysed systematically for this paper. ${ }^{3}$ A third aim of this paper is to place the phonetic changes to the two $\bar{e}$ 's in a wider context of long-vowel changes in the ME period.

\section{Data and method}

The evidence for OE $\bar{e}$ is culled primarily from A Linguistic Atlas of Early Middle English (LAEME; Laing 2008). As all LAEME sources have been dated and most of them have been localised, it should be possible to determine (a) the orthographic reflexes (across time and space), and (b) the sound correspondences - including any changes - of the two OE $\bar{a}$ 's in the regional varieties of ME. I have examined additional data from A Linguistic Atlas of Late Mediaeval English (LALME; McIntosh, Samuels \& Benskin 1986) and A Survey of Middle English Dialects, c. 1290-1350 (SMED; Kristensson 1967, 1987, 1995, 2001, 2002). For early Modern English (ModE), I have consulted Zachrisson (1913) and Dobson (1968), who report the statements of the early ortho-epists.

From $L A E M E$, all spellings for a number of words with $\mathrm{OE} \overline{\alpha e}$ have been extracted and counted, and the words have been divided into groups according to their origin, $\bar{e}^{l}$ or $\bar{e}^{2}$, as far as this has been possible to establish. The Oxford English Dictionary Online was used to check the etymologies of the relevant words, and only words whose etymology was certain were included. Hence, forms for the following lexical items were counted in localised sources.

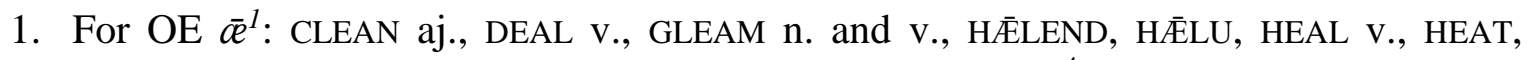
HEATHEN aj. and n., LEAD v., TEACH, WHEAT (1342 tokens). ${ }^{4}$

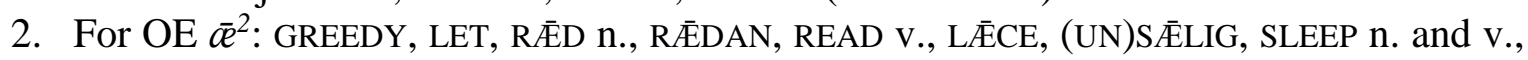
SPEECH, STREET (1502 tokens).

For the verbs, forms for the infinitive, imperative, indicative plural, and 1. singular present indicative were counted. The LAEME spellings are found in Table 3 and Table 4 in the Appendix. In the discussion, forms with $\langle\mathrm{a}\rangle,\langle\mathfrak{x} / \mathrm{ae}\rangle$ and $\langle$ ea $\rangle$ have been treated together, as it seems sensible to assume that these spellings all correspond to a front mid-to-open vowel.

\footnotetext{
${ }^{3}$ In $L A E M E$, there are five tokens for STREET as a suffix, all of which have <e>; they appear in sources localised to Gloucestershire (\#10), Herefordshire (\#246), Worcestershire (\#173), Norfolk (\#1400) and York (\#296). The simplex is rather more frequent, and all except eight tokens have $\langle e(e)>$; four tokens have $\langle a>$, in a source from Essex (\#4), and four tokens have $\langle æ\rangle$, in a source from Worcestershire (\#278); the latter also has one form with $<\mathrm{e}>$.

${ }^{4}$ Forms for the noun DEAL (with $\bar{e}^{l}$ ) were also extracted, but as OE also had $d \bar{a} l$ besides $d \bar{c} l$, these forms were not included in the tables. Additionally, all spellings for THERE, WHERE, HAIR (OE $\left.\bar{e}^{2}\right)$ and EVER, NEVER (OE $\left.\bar{\alpha}^{l}\right)$ were counted, but their developments are idiosyncratic: They develop into PDE /eə/ and /e/, respectively, rather than to PDE /i:/. Therefore, their spellings have not been reported here; the interested reader is referred to Stenbrenden (2016, Ch. 3). Nor has LADY $\left(\bar{\alpha}^{I}\right)$ been counted, as it also has a different development (seen in the fact that it has $\mathrm{PDE} / \mathrm{eI} /$ rather than /i:/): The vowel of the first syllable underwent early shortening and joined ranks with $\operatorname{eME} a$, which lengthened to [a:] in ME Open Syllable Lengthening, and eventually vowel-shifted to /eI/. The vowel of HEALTH $\left(\bar{\alpha}^{I}\right)$ similarly shortened and has not been counted; the same applies to DEAD and DREAD (with $\bar{\alpha}^{2}$ ).
} 


\section{Discussion and findings}

The following discussion is based on the spellings and figures reproduced in Table 3 and Table 4 (Appendix). But first, an observation on the use of $\langle\mathfrak{x}\rangle$ in ME. As stated in the introduction, Wright \& Wright claim that traditional $\langle æ\rangle$ was 'preserved in writing until about the end of the twelfth century, and occasionally even later' (1928: §52). The LAEME data show, however, that $\langle\mathfrak{x}\rangle$ was in fact retained much longer - at least by certain scribes - in some cases into the late thirteenth or early fourteenth century, cf. Table $1 .^{5}$ Whether this counts as 'occasional' is for the reader to judge. Wyld (1914: §161) is more accurate in his assessment, stating that $\langle\mathfrak{x}\rangle$ 'is found comparatively rarely after the thirteenth century, and probably not at all after the beginning of the fourteenth'.

Table 1. Incidence of $\langle\mathfrak{x}\rangle$ for OE $\overline{\boldsymbol{e}}$ in $L A E M E$ sources dated after 1200

\begin{tabular}{|c|c|c|c|}
\hline No. & Loc. & Date & Lexemes with $\langle\mathfrak{x}\rangle$ \\
\hline 304 & $\mathrm{Ha}$ & 1200 & H㐫LU , LEAD V., TEACH, LET \\
\hline 64 & Ex & $1200-24$ & 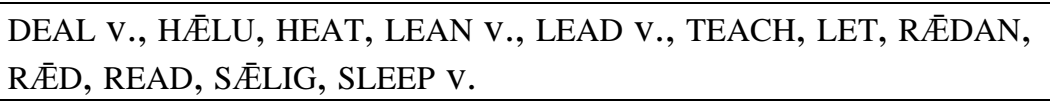 \\
\hline 1900 & Wor & c. 1200 & H㐫LU \\
\hline 157 & Som & c. 1240 & LET \\
\hline 6 & Wor & c. 1250 & LEAD V., READ \\
\hline 7 & Wor & c. 1250 & LEAD v. \\
\hline 11 & Ex & 1258 & DEAL n., RĀED \\
\hline 277 & Wor & $1250-74$ & DEAL n., LEAN v., LEAD v., RĀDAN, R ĒD, SLEEP v., SPEECH \\
\hline 278 & Wor & $1250-74$ & 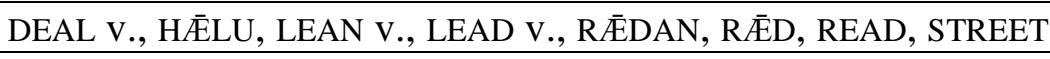 \\
\hline 131 & Nfk & $1272-1302$ & TEACH \\
\hline
\end{tabular}

$\mathrm{OE} \overline{a e}^{1}(<\mathrm{W} \mathrm{Gmc} a i+i)$ is believed to have been [æ:] in all OE dialects except Kentish, where it was [e:]. Tables 3 and 4 (Appendix) show that <e>-type spellings greatly preponderate in Kent for the reflexes of both OE $\bar{\alpha}^{1}$ and $\bar{\alpha}^{2}$, as expected. The two <ae> forms for $\bar{\alpha}^{1}$ cannot change the conclusion reached by all previous scholars that Kentish had [e:] for both OE $\bar{x}$ 's (despite Hogg 2011: $\$ \$ 3.22-3.25$ ). In the rest of the country also, <e> is the dominant spelling from the earliest period covered by LAEME (1150-1250), but even more so in the later period (1250-1350). Moreover, $\langle\mathrm{e}\rangle$ is more frequent in the East Midlands, the South-East and the North (at $78.8 \%, 94.74 \%$, and $90.15 \%$ respectively, for the entire period $1150-1350$ ) than in the West Midlands (at $66.97 \%$ for the entire period); this is obviously connected to the high number of $\langle$ ea $>$ in the West Midlands, to which I will return later. Numbers for the South-West are so low as to preclude any conclusion. The preponderance of $\langle\mathrm{e}\rangle$ is a little surprising: If $\mathrm{OE} \bar{\alpha}^{1}$ really was [æ:] generally in Saxon and Anglian dialects, one would expect a greater proportion of $<\mathrm{a} / æ / a e / e a>$ forms, at least in the early period. Still, their infrequency may not be enough to contradict the conventional account. At least, this is Kristensson's conclusion based on analysis of the SMED material (2001: 40). It is also perfectly possible that the reflex of OE $\bar{e}^{l}$ was [æ:] in OE, but started to raise early, and so had reached [ $\varepsilon$ :] before 1150 , for which $\langle\mathrm{a} / \mathfrak{\text { }}\rangle$ may have been deemed inappropriate by the scribes. Of course, it is possible to read too much into the (non-)survival of $\langle\mathfrak{x}\rangle$ in early ME dialects and scribal systems, and changes in orthography may have no phonetic correlate. However, when changes in orthography are systematic, either in terms of their dating/locus or in respect of how many scribes have adopted the new orthographic pattern, the likelihood that they do indeed reflect pronunciation changes is increased. Such is the case here.

\footnotetext{
${ }^{5}$ Table 1 contains only lexemes extracted for analysis in the present paper.
} 
The minor <ai/ay/æi/ei> forms are difficult to interpret (see Table 4 and Table 6 in the Appendix). If taken at face value, they indicate diphthongs similar or identical to those in words with an etymological diphthong (like OE $c \bar{a} g$ ' $k e y$ '), which is not impossible. The $\langle\mathrm{i} / \mathrm{y}\rangle$ may also be used as a diacritic device to indicate either a closer vowel, or vowel length (as in Older Scots); such diacritic use of $\langle\mathrm{i} / \mathrm{y}\rangle$ in the $L A E M E$ corpus has been reported elsewhere (e.g. Stenbrenden 2016 : 108). It is here that considerations of scribal habit and practice may be useful: more detailed analysis of the relevant scribal profiles may reveal whether or not they were capable of using letters diacritically. ${ }^{6}$ Use of <ai/ay/æi/ei> is confined to the North and the West Midlands (cf. Table 6), with the exception of two texts from East Anglia: \#1300 from Suffolk has 1 <ai> for $\bar{e}^{2}$ (HAIR), and \#285 from Norfolk has $1<\mathrm{ei}$ > for $\bar{e}^{1}$ (SEA). In Northern texts, there are $12<$ ai>-type spellings for $\bar{e}^{l}$ and 2 for $\bar{e}^{2}$, whereas for the West Midlands the numbers are 3 and 5, respectively. A few scribes use <ai>-type forms for both $\bar{\alpha}$ 's, but the majority use <ai/ei> etc. for only one of the $\bar{a}$ 's. Lexically, there are some 'repeat offenders': in the North, <ai>-type spellings occur for the (stressed) vowel of HEAT, HEATHEN, H㐫LU, SEA

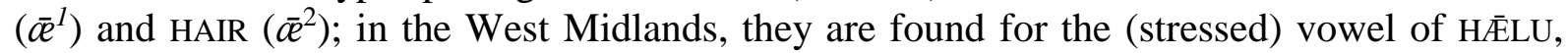
CLEAN, LEAD $\left(\bar{e}^{1}\right)$ and RềD, HAIR $\left(\bar{e}^{2}\right)$. At least for the North, the proportions of different spellings for the two $\bar{e}$ 's are statistically highly significant, even with the preponderance of $\langle\mathrm{e}>$ for both $\bar{a}$ 's.

When $\langle\mathrm{a}\rangle$, $\langle$ ai $\rangle$ and $\langle\mathrm{e}\rangle$ are measured as separate categories, the chi-square is 13.4382 with a $p$-value of .001208 . The result is significant at $p<.01$. Given that the percentages of $\langle\mathrm{e}\rangle$ for both $\overline{a e}$ 's in the North are almost identical $\left(90.15 \%\right.$ for $\overline{\alpha e}^{1}$ and $90.68 \%$ for $\left.\bar{\alpha}^{2}\right)$, it must be the proportions of $\langle a\rangle v s$. $\langle a i / a y\rangle$ which are responsible for this effect. The question is thus how to interpret the <ai/ay> forms - are they indicative of a diphthong or simply of a long, possibly retracted $\overline{c e} / \bar{a}$ [æ: $\sim \mathrm{a}:]$ (with $<\mathrm{i} / \mathrm{y}>$ used as a diacritic device)? If so, the different proportions in Northern sources cannot matter (as is confirmed by the chi square test), since there are 13 $<\mathrm{a} / \mathrm{ai} / \mathrm{ay}>$ for $\bar{\alpha}^{1}$, and $11<\mathrm{a} / \mathrm{ai} / \mathrm{ay}>$ for $\bar{e}^{2}$. We are thus back to the interpretation of the $<\mathrm{i} / \mathrm{y}>$ element in <ai/ay> digraphs; to assess their role, the orthographic system of one LAEME text with $1<\mathrm{ei}>$ for $\bar{e}^{1}$, \#295 from the West Riding of Yorkshire (dated c. 1300-50), will be examined in some detail in what follows. \#295 has <ai> and <ay> very consistently for etymological $a i(<\mathrm{OE} a g)$ and $e i(<\mathrm{OE} e g)$ as well as for $a i$, $e i$ in French loans, e.g. in AGAIN, AGAINST, AWAY, CLAY, DAY, EITHER, FAIR, HAIL, MAIDEN, MAY, NAIL, NAY, RAISE, SAY, WAY; AIR, AVAIL, HEIR, PRAY, TRAITOR. Generally, <ei/ey> are not used for the etymological diphthongs. $\mathrm{OE}\langle\mathrm{p}\rangle$ and $\langle\partial\rangle$ are consistently $\langle\mathrm{y}\rangle$ or $\langle$ th $\rangle$. There are a few back spellings with $<$ a $>$ for the etymological diphthongs $a i$ and $e i$; i.e. $1<$ falid $>$ (beside $1<$ failld $>$ ) for the 3 . person sing. preterit of FAIL, and 3 <slan> (besides $1<$ slain> and 1 <slaym>) for the past ppl. of SLAY, and $5<$ sla $>$ for the infinitive of SLAY. These may suggest that $\langle\mathrm{i} / \mathrm{y}\rangle$ merely indicate vowel length, as it is unlikely that SLAY was ever pronounced with [a: $\sim \mathrm{a}:]$, unless it is confused with the cognate ON slá 'to strike, hit'. Alternatively and less likely, they indicate that the value of <a> had diphthongised already (ME /a:/ > [æi عi]). \#295 also has 'unetymological' (possibly diacritical) $\langle\mathrm{i} / \mathrm{y}\rangle$ in the following lexemes, which had a long monophthong in West-Saxon: 1 <beit> for the past ppl. of BËTAN; 1 <braith> for BRĀP; 7 <broiyer-> for BROTHER; 1 <deid> for DEATH; $1<$ gait $>$ for the 3. person sing. preterit of GITAN; $1<$ heiten $>$ for the past ppl. of HĀTAN; 1 <laith> for LOTH; 1 <Rais> for the 3. person sing. preterit of RISE; 1 <seir> for SËR; 1 <wayth> for VĀPI. It should be noted that these spellings in most cases appear alongside completely traditional spellings. The forms adduced appear to support the interpretation that $\langle\mathrm{i} / \mathrm{y}\rangle$ are used

\footnotetext{
${ }^{6}$ Ideally, all the scribal profiles of $L A E M E$ should be submitted to such close analysis, but that is not possible in this paper, as remarked in the Introduction, for reasons of time and scope: virtually all the scribal texts in $L A E M E$ have instances of one or both $\alpha$ 's and would thus have to be analysed along these lines.
} 
to indicate vowel length. However, as <ai/ay> are used so consistently for the etymological diphthongs, a diphthongal interpretation cannot be ruled out entirely - the scribe clearly knows what diphthongs are and how to spell them. The interpretation of such <ei/ey> and <ai/ay> for $\bar{a}$ may thus be as elusive as ever.

Jordan (1925: $\S 48$, Anm.2) states that OE $\bar{\alpha}^{1}$ raised before 'dentals' in the North and the East Midlands; it is clear from his examples that the 'dentals' in question are the alveolar consonants /t d l n/; perhaps 'coronal' would be a better term, as the precise pronunciation of these sounds in the period covered remains uncertain. Jordan seems to say that this raising started in OE, but he quotes examples from ME texts, e.g. the Ormulum and Havelok. Kristensson, however, finds no evidence for this change in the SMED data $(1987: 47 ; 1995: 24 ; 2001: 40)$. The material examined here shows almost exclusively $\left\langle\mathrm{e}(\mathrm{e})>\right.$ for $\mathrm{OE} \bar{e}^{1}$ in the northern sources, regardless of the phonetic context, but the northern material in $L A E M E$ is generally very late: all but one of the sources have been dated to the period 1300-1350; only \#151 from Lancashire is somewhat earlier and has been dated to the period 1275-1299. Similarly, the SMED sources are from the period 1290-1350. By this date, the reflex of $\bar{e}^{l}$ must have raised generally across the country anyway, and the dominant spelling is $\langle\mathrm{e}(\mathrm{e})\rangle$ everywhere. Table 5 in the Appendix shows the incidence of <e/ee/éé> for $\bar{e}^{l}$ in $L A E M E$ sources dated before AD 1200: most of the $<$ e>-type spellings do indeed appear before a dental or alveolar consonant, but since in any case most of the words examined in fact have an alveolar postvocalic consonant, I find it difficult to draw any conclusions regarding this supposed sound-change from the material examined here. ${ }^{7}$

OE $\bar{a}^{2}$ is supposed to be [æ:] only in Saxon dialects, and [e:] in Anglian and Kentish; Campbell (1959: §257) believes the split goes back to the Continental phase. The exact boundary is of course difficult to establish (cf. Wyld 1914: §162), but Brandl (quoted in Kristensson 1967: 57) finds it started at the Severn, cut right across Worcestershire and the southern part of Warwickshire, then followed the southern border of Northamptonshire. In the East, things are a little less clear, but Brandl appears to state that the dividing line followed the western border of Cambridgeshire and Huntingdonshire. North and east of this line, there was Anglian [e:]; south of this line, there was Saxon [æ:]. Kristensson agrees for the most part (1987: 51-2, Map 6; 1995: 28-32, Map 4), except that he thinks the boundary cut across Northamptonshire in a north-easterly direction, then followed the southern border of Peterborough and Ely to the Wash. Thus, Ely, Cambridgeshire, Huntingdonshire, Bedfordshire, Buckinghamshire and Oxfordshire were Saxon territories, in Kristensson's opinion, and the south-eastern part of Northamptonshire and most of Gloucestershire, except for the northern-most tip, were also [æ:] areas. Kitson (1998: 176) finds Kristensson's account much too simplified, and it is certainly not always clear whether Kristensson thinks of these areas as politically Saxon, or linguistically Saxon. For our purposes, it need not matter.

Kristensson (2001: 44) argues that East Anglia had a large Saxon population, and thus must have had [æ:] for OE $\bar{e}^{2}$ rather than the expected Anglian [e:]. Besides, OE $\bar{\alpha}^{2}$ is supposed to have retracted to [a:] in East Saxon dialects. Kristensson's isogloss for this retracted [a:] includes Essex, Hertfordshire, Bedfordshire, Huntingdonshire, Middlesex, and most of Cambridgeshire (1995: 31). In the LAEME data, frequent and dominant $\langle\mathrm{a}\rangle$ in the material from Essex (Table 4) supports East Saxon retraction there, but not at all in the rest of the supposedly East Saxon territory. The domain of this retraction therefore seems not to extend beyond Essex in the time period covered by $L A E M E$. This is remarkable, given what Kristensson concludes from the SMED material, which is generally dated 1290-1350 and thus

\footnotetext{
${ }^{7}$ A thorough investigation of (late) OE sources might settle the case, but that is beyond the scope of this paper.
} 
overlaps with the later $L A E M E$ material. One important difference regarding the material in $\angle A E M E$ and $S M E D$, however, is that the latter is comprised of onomastic data and so contains a rather high number of shortened forms for OE strōet 'street', which traditionally have been used to establish the isogloss between Anglian $\bar{e}$ and Saxon $\bar{e}$ for $\bar{\alpha}^{2}$, cf. the last paragraph of section 1. Tables 3 and 4 show that $\langle\mathrm{a}\rangle$ is recorded for $\bar{c}^{2}$ in the West Midlands also, but one would tend to interpret it as corresponding to Saxon [æ:] rather than as evidence of retraction. However, <a/æ/ea> are indeed slightly more common in the East Midlands than in the West, which might indicate retraction, or else simply retention of [æ:], in Saxon areas. The story of $\bar{e}$ perhaps better than that of any other vowel illustrates the difficulty linguists face when they attempt to infer the phonetic correspondences of ME spellings.

Above all, analysis of the $L A E M E$ material reveals that the reflexes of the two $\bar{e}$ 's are not kept apart as systematically as expected in Anglian (or indeed anywhere). In the South-East, $\langle\mathrm{a} / \mathfrak{x}\rangle$ are of course very rare, but do occur. In other places, on the other hand, <a/æ/ea> are very common, not just for $\bar{\alpha}^{1}$, but also for $\bar{\alpha}^{2}$. Sources localised to the South-West Midlands should in principle have the same number of $\langle\mathrm{a} / \mathfrak{x} / \mathrm{ea}\rangle$ for both $\bar{e}$ 's - being the heart of the West-Saxon territory - but that is not the case: $\left\langle\mathrm{a} / \mathfrak{a} / \mathrm{ea}>\right.$ are more frequent for $\bar{e}^{l}$. The total number of tokens is very low, and any conclusions must be highly tentative, but if this pattern has any significance at all, it suggests that the value of $\bar{c}^{2}$ may always have been a little closer than that of $\bar{e}^{1}$, even in Saxon, and even if it goes back to West Gmc $\bar{a}$, which a priori would suggest a more open value. West Gmc $\bar{a}$ supposedly goes back to PrGmc $\bar{\alpha}$ (Campbell 1959: §§127-130), so one can only speculate as to the concrete phonetic realisation(s) of $\bar{e}^{2}$, in $\mathrm{OE}$ as well as in ME. Hogg (2011: $\S \S 3.3,3.22-3.25$ ) argues that PrGmc $\bar{e}$ remained in W Gmc, being /a:/ but phonetically [æ:]. His reasoning is that since PrGmc $\bar{\alpha}$ was the only low long monophthong, there was no phonemic front-back opposition, so that /æ:/ may have had a number of allophones, front [æ:] or [a:], and back [a:], as evidenced by later developments. ${ }^{8}$ (The same argument applies to the short low vowel /a/.) 'It therefore follows that the alleged OE, OFris shift of */a:/ > /æ:/ is an artefact of phonemic theory, and that there is no reason to suppose that [...] the Gmc long low vowel retracted significantly at any period in the development of OE' (Hogg 2011: 60), because it had been [æ:] all along. ${ }^{9}$ The dating of the Anglian raising of this $\bar{e}^{2}$ to $\bar{e}$ is unclear, in Hogg's opinion (2011: 61; but see his footnote 2 on p. 61). If Hogg's hypothesis is correct, it entails that the realisation of $\bar{e}^{2}$ may not have been lower than that of $\bar{e}^{1}$ (the $i$-mutated product of $\mathrm{W}$ Gmc ai).

Furthermore, another question raised by the ME spellings is whether $\bar{e}^{2}$ really was [e:] in Anglian; there cannot be any doubt that Kentish had [e:]. Wyld claims quite specifically that 'This non-W.Sax. $\bar{e}$ was tense' (1914: $§ 120)$, i.e. [e:] rather than [ $\varepsilon$ :]. If so, the overwhelming majority of forms should have $\langle\mathrm{e}\rangle$, which they generally do. ${ }^{10}$ Still, there is a fair number of forms with $\langle\mathrm{a} / \mathfrak{e} / \mathrm{ea}\rangle$ : do these correspond to an opener sound, or simply reflect the conservative (WS) nature of spelling? A possibility is that not just non-WS $\bar{e}^{2}$, but non-WS $\bar{e}^{1}$ also, had raised by this stage, so that the reflexes of both $\overline{a e}$ 's had merged, but were somehow phonetically separate from the reflex of $\mathrm{OE} \bar{e}$, and were thus distinguished orthographically by whatever means (other than <e>) that the scribes found useful. A statistical analysis of all LAEME

\footnotetext{
${ }^{8}$ The latter allophone is likely to have occurred before nasals, since the later development is to /o:/, as in OE and Old Frisian mōna 'moon'.

${ }^{9}$ One could argue that the W Gmc phoneme should be /æ:/ rather than /a:/, if it remained essentially unchanged from PrGmc, but Hogg's solution has the advantage of covering the later development in all the W Gmc languages.

${ }^{10}$ In fact, non-WS should have exactly the same spellings for OE $\bar{e}^{2}$ as for OE $\bar{e}$. Previous analyses suggest that such is not the case (Stenbrenden 2016), but conducting a thorough comparison of spellings for the two vowels in non-WS is clearly a topic for further research.
} 
spellings for $\mathrm{OE} \bar{e}$ and both $\bar{e}$ 's may support or refute such a hypothetical, albeit plausible, course of events, but is beyond the scope of the present paper (cf. footnote 11).

Orm's spellings are worth considering in some detail in this context. From the portion tagged for LAEME \#301 (the Dedication and Preface, and parts of the Introduction and Homilies), I have extracted and counted all forms for words with $\mathrm{OE} \bar{e}^{1}$ and $\bar{e}^{2}$, except (a) those forms which show a shortened vowel in Orm's language (i.e. are followed by a double consonant), and (b) those words whose etymology is uncertain (in terms of which $\bar{e}$ they go back to). Thus, 107 tokens with $\bar{e}^{1}$ were counted, of which 3 have $\langle\mathrm{a}\rangle$ (ANY, NE+ANY, LADY), 68 have $\langle\mathfrak{x}\rangle$,

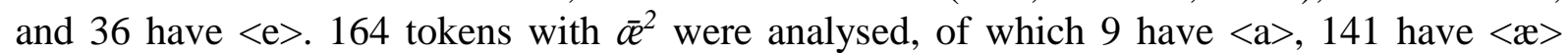
(including the highly frequent THERE, which has $\langle\mathfrak{x}\rangle$ in all 110 tokens), and 14 have $\langle\mathrm{e}\rangle$. A chi square test reveals that the two vowels have highly significantly different spellings $(p<$ 0.00001) in the Ormulum, both when $\langle\mathrm{a}\rangle$ and $\langle\mathfrak{x}\rangle$ are amalgamated and measured against $\langle\mathrm{e}\rangle$, and when all three spellings are measured separately. ${ }^{11}$ Clearly, $\langle\mathfrak{x}\rangle$ is the dominant spelling

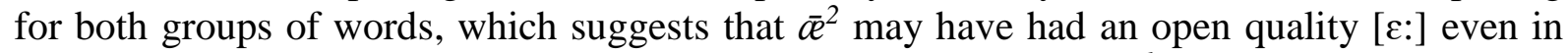
Orm's dialect. On the other hand, the higher proportion of $\langle\mathrm{e}\rangle$ for $\bar{e}^{l}$ may indicate, somewhat surprisingly, a closer quality for $\bar{e}^{1}$ than for $\bar{\alpha}^{2}$. Wyld (1914: §161) thinks Orm's 〈æ> spellings are 'remarkable', since his Anglian dialect should have $\bar{e}$. In Wyld's opinion, the $<\mathfrak{x}>$-forms 'must probably be attributed to the domination and persistence of the classical W.Sax. mode of writing among learned persons like Orm' (1914: §161). This is quite possible, although any 'domination and persistence' of the late West-Saxon standard 'mode of writing' is not exactly in evidence elsewhere in Orm's system. Given Orm's obviously good ear, I propose that his spellings be taken at face value, as suggesting at the very least that there was a system(at)ic difference in sound, however small, between the reflexes of OE $\bar{e}$ and the two $\bar{x}$ 's even in Anglian. The significant difference in his spellings of $\bar{c}^{1}$ and $\bar{\alpha}^{2}$ may even suggest a three-way distinction. It could also be that the reflex of $\bar{\alpha}^{2}$ was felt to be more similar to that of $\bar{e}^{1}$ than that of $\bar{e}$. Whether this difference was phonemic is another question entirely. (A similar case might be seen in modern French, in which $e ́[\mathrm{e}(:)]$ and è $[\varepsilon(:)]$ are kept apart in spelling as well as in pronunciation, even if the difference does not reach phonemic status: their distribution is largely predictable from the phonetic context and the syllable structure; cf. Girard Lomheim \& Lyche 1991, section 3.2.1.3.) Even if alphabetic writing is essentially phonemic (at least at the outset), that does not prevent scribes from observing sub-phonemic details and differences, especially if they are clearly noticeable.

Wyld also offers some statistics regarding spellings for both $\bar{e}$ 's in southern texts, and he concludes that ' $e a$ is written with far greater consistency for' $\bar{e}^{l}$ than for $\bar{e}^{2}$ (1914: $\left.\S 161\right)$. This indicates an opener quality of $\bar{e}^{l}$, which is the opposite of my conclusions regarding Orm's system. However, Wyld continues, 'but the identity of the sounds is proved by the fact that $e$, $e a, a$ are written indifferently for both and further from such rhymes as pēere-wēre, drēenlöeden' (1914: §161). He thus seems to believe that the two $\bar{a}$ 's were identical in southern ME, certainly from the later thirteenth century onwards. This view seems to be supported (for the whole country) by the fact that the same spellings are found for both $\overline{\alpha e}$ 's in most counties, as laid out in Table 4 (Appendix): that is, $\langle\mathrm{a}\rangle,\langle\mathfrak{}\rangle,\langle\mathrm{ea}\rangle,\langle\mathrm{e}\rangle,\langle\mathrm{eo}\rangle,\langle$ ai/ei $\rangle$ are found for both $\vec{a}$ 's. However, the proportions vary, and this is indeed the point: in the absence of clearly distinct letter-sound correspondences, it is the fact that there are dominant vs. minor spelling variants that allows us to postulate a potential pronunciation difference. In fact, a chi square test including all spellings for the two $\bar{x}$ 's as summed up in the final row of Table 4 (excluding

\footnotetext{
${ }^{11}$ When the three spellings are counted separately, the chi-square statistic is 27.4009 . The $p$-value is $<0.00001$. The result is significant at $p<.01$. Similar chi square tests could be calculated for all scribal systems in $L A E M E$, but the aim of this paper is rather to show the totality of the spellings for the two $\bar{e}$ 's in the relevant period.
} 
$\langle e o\rangle$ and the very infrequent $\langle\mathrm{i}\rangle,\langle\mathrm{y}\rangle,\langle\mathrm{ia}\rangle$ and $\langle\mathrm{o}\rangle$, because numbers lower than 5 may affect the validity of the test), indicates that the difference in the spellings of the two vowels is highly significant $(p<0.00001) .{ }^{12}$ Overall, the spellings point to a closer quality of the reflex of $\bar{e}^{2}$, which is as expected.

Regarding the 'new' ME digraph <ea>, or rather its new use for OE $\bar{\alpha}$, the material from $L A E M E$ suggests very strongly that it was a West Midlands 'innovation'. In the early period, <ea> reaches a percentage of 41.16 for $\bar{e}^{l}$ here, which is all the more remarkable given its almost complete absence from the East Midlands material (for either $\bar{\alpha}$ in any period). Forms with <ea> are especially frequent in Shropshire, Cheshire, Worcestershire and Herefordshire, some of which must have been Anglian territory, politically and/or linguistically. For $\bar{e}^{2}$, however, forms with <ea> reach only 7-8\% in the West Midlands (7.72\% for the entire period). The question, therefore, is whether use of $\langle$ ea $>$ arose as a means to distinguish the two $a$ 's orthographically, especially given the change $\mathrm{OE} \bar{e} a\rangle \bar{e}$ and the ambiguity of $\langle\mathrm{e}(\mathrm{e})\rangle$. In this context, <ea> for the short eME $a, e a$ (whose reflexes had merged) may in fact have acted as a 'bridge' for the long vowel. Lass \& Laing (2012: 81) examine all the lexemes for which <ea> is used in $L A E M E$ and find that it was used for what they call 'opener front' vowels. They conclude that it was something like a diacritic device indicating a more open $e$-type sound (2012: 92-95), with which I agree. Essentially, the same rationale lies behind both $\langle\mathfrak{x}\rangle$ and $<e a>$ : they are composed of ' $\mathrm{e}$ ' and 'a' and correspond to a sound intermediate between $[\mathrm{e}(:)]$ and $[\mathrm{a}(:)]$; it is only the relative chronology of the two parts that differs.

As long as <ea> continues to be used in ME sources, it is possible that the more open quality [ $\varepsilon:]$ may have persisted. On the other hand, the earliest evidence of vowel shift of OE $\bar{e}$ to [i:] appears around 1200-1250, but the conventional spelling $\langle\mathrm{e}(\mathrm{e})>$ remains, as it does to the present day. Therefore, the reflex of ME $\bar{e}$ may in fact also have raised, to [e:], around this date - or later - and <ea> simply remained for conventional reasons. All we know for certain is that the two reflexes are generally kept apart (for instance in rhymes) into the early ModE period, when they merged at /i:/ in some dialects. But whether they were kept apart as [e:] and [e:], as conventionally believed, or as [i:] and [e:], is an issue open to argument and to which I will return later.

At this point, it is worth clarifying some principles regarding the chronology and nature of the great vowel shift and the process commonly referred to as ME 'open syllable lengthening' (MEOSL). Briefly, short vowels were lengthened in open syllables at some point during ME, and it seems as if they were simultaneously lowered, e.g. eME ivel > ME êvel EVIL (Ritt 1994; Lutz 2004). Conversely, when long vowels are shortened, the resulting short vowel seems to have been simultaneously raised, e.g. eME sēk > ME sick SICK. However, if the 'Early Vowel Shift Hypothesis' suggested by Stockwell (1985) and Stockwell \& Minkova (1988a, 1988b) is correct, and I have concluded previously that it is (Stenbrenden 2016), there is no need to postulate a lowering process for lengthened vowels or a raising process for shortened vowels, as isolative short-vowel raising is historically very rare. ${ }^{13}$ In other words, if the vowel shift was already under way when MEOSL started, the new long vowels from MEOSL simply merged with the closest etymological long vowel, which had already been raised in the vowel shift. Thus, the new long vowels from MEOSL merely seem to have been lowered, and the new short vowels only appear to have been raised, because their spellings have changed, but the spellings correspond to a different phonetic reality (Stockwell 1985: 310-311).

\footnotetext{
${ }^{12}$ The chi-square statistic is 66.7755 . The $p$-value is $<0.00001$. The result is significant at $p<.01$.

${ }^{13}$ It has occurred combinatively, especially before nasals or as a result of vowel harmony (Campbell 1959: §111; Hogg 2011: 64-65; Ringe \& Taylor 2014: 62).
} 
On the topic of vowel shift: The raising of eME [æ:] is in evidence from the mid-thirteenth century. Forms with $\langle\mathrm{i}\rangle$ and $\langle\mathrm{y}\rangle$ are found very early, in sources dated to the period 12501330 (LAEME, SMED), as indicated in Table 2 (in which the first three spellings are from $\angle A E M E$ and the remaining from SMED). The lexical 'leader' in this change may have been SILLY (< OE sälig). It is unlikely that the vowel of SILLY, or of the other words in Table 2, demonstrates raising of a short vowel (which must have arisen from shortening of the long $\mathrm{OE}$ vowel) for the following reasons. First, as pointed out in the preceding, unconditioned shortvowel raising is rare in English; second, and with the first argument in mind, regular (early) vowel shift of $\mathrm{OE} / \mathrm{eME} \bar{e}>\bar{e}>\bar{l}$, then shortening to $i$, is a more economical development than $\mathrm{OE} / \mathrm{eME} \bar{a}>a>e>i$. It is more economical because it involves the well-known stages of the vowel shift of $\bar{e}>[\mathrm{i}:]$, then well-attested shortening to a vowel of the same height, whereas the alternative involves shortening to a vowel of the same height, then raising of that short vowel in two stages. ${ }^{14}$ Yet, variants with [e:], [e:] and [i:] probably co-existed for a long time, given the non-merger in ME between the reflexes of eME $\bar{e}$ and $\bar{e}$ (from whatever source); as noted above, this merger did not take place until the sixteenth century at the earliest (Zachrisson 1913: 204; Dobson 1968: 610). In this respect, it makes sense to distinguish between the standard language and regional/social variants: in the latter, the merger may have taken place earlier.

Table 2. Early vowel-shift spellings for OE $\bar{a}(L A E M E, S M E D)$

\begin{tabular}{|c|c|c|c|}
\hline County & No. & Date & Spelling \\
\hline Worcestershire & 278 & $1250-74$ & <spiche> SPEECH $\left(\bar{\alpha}^{2}>\right.$ non-S $\left.\bar{e}\right)$ \\
\hline Mixed (NE\&SW) & 214 & $1275-99$ & $\left\langle\right.$ silly> SËELLIG $\left(\bar{\alpha}^{2}>\right.$ non-S $\left.\bar{e}\right)$ \\
\hline Lincolnshire & 159 & c. 1300 & $<$ lydy> LEAD 1.sg.ps. $\left(\bar{a}^{l}\right)$ \\
\hline West Riding, Yks & - & 1327 & $<$ Minskip $>\left(\bar{a}^{l}\right)$ \\
\hline Lincolnshire & - & 1327 & $\left\langle\right.$ Silyman $>\left(\bar{e}^{2}>\right.$ non-S $\left.\bar{e}\right)$ \\
\hline Huntingdonshire & - & 1327 & $\left\langle\right.$ Silly $>\left(\bar{a}^{2}>\right.$ non-S $\left.\bar{e}\right)$ \\
\hline Suffolk & - & 1327 & <Rydelingfeld > $\left(\bar{\alpha}^{2}>\right.$ Saxon $\left.\bar{\alpha}\right)$ \\
\hline Dorset & - & 1327 & $<$ <idelyngton $>\left(\bar{a}^{2}>\right.$ Saxon $\left.\bar{\alpha}\right)$ \\
\hline Somerset & - & 1333 & $\left\langle\right.$ Brych $>\left(\bar{\alpha}^{2}>\right.$ Saxon $\left.\bar{\alpha}\right)$ \\
\hline
\end{tabular}

Of the spellings reproduced in Table 2, the forms from Dorset and Somerset almost certainly indicate early vowel shift of $\bar{\alpha}^{2}$ in the South-West, as does the Suffolk form in the South-East Midlands; the forms from the West Riding of Yorkshire and Lincolnshire probably indicate vowel-shift raising of $\bar{e}^{l}$. The remaining forms demonstrate vowel shift of non-Saxon $\bar{e}$. In so far as it is possible to conclude anything on the basis of such a low number of forms, the SouthWest, the SE Midlands and the North-East stand out as loci of change. Incidentally, the same areas stand out with respect of early vowel-shift spellings for the other ME long monophthongs too (Stenbrenden 2016: Ch. 9).

Lutz (2004) sees the early ME raising of OE /æ:/ to [ع:] as a prelude to the great vowel shift, making the latter a push-chain process in traditional terminology (cf. Jones 1989: 127-141). ${ }^{15}$ To determine whether this claim is supported by the spellings, the remainder of this section

\footnotetext{
${ }^{14}$ Shortening of long vowels, e.g. $\bar{l}$ to $i$, is commonplace in words of more than one syllable, but is also seen in some frequent monosyllabic words in late ME or early ModE, such as FOOT, GOOD, but only after the vowel shift had raised the etymological long vowel, cf. Wells (1982: 198).

${ }^{15}$ Jones refers to the changes to OE $\bar{a}$ and $\bar{x}$ as 'The first English vowel shift' (1989: 137), and clearly sees them as instances of (some of) the same tendencies that are observed in the later great vowel shift, i.e. increased palatality $(\bar{e})$ and labiality $(\bar{a})(1989: 127-136)$.
} 
seeks to establish the chronology of the full set of ME long-vowel changes, in order to place the changes to $\mathrm{OE} \bar{a}$ in the bigger picture.

I concluded in earlier work (Stenbrenden 2010, 2016) that the traditional GVS changes started around 1250, and that they began with the simultaneous raising of eME $\bar{e}$ and $\bar{o}$ and diphthongisation of eME $\bar{l}$ and $\bar{u}$. This lends support to the 'Early Vowel Shift Hypothesis' alluded to earlier. The changes affecting the two low vowels, OE $\bar{a}$ and $\bar{p}$, are not usually considered part of the GVS, even if they are similar in nature. The main reason has been their dating: OE $\bar{a}$ seems to have started raising in the late eleventh century (Stenbrenden 2016: 58), and the raising of $\mathrm{OE} \bar{\alpha}$ appears to have been on its way certainly in the twelfth century, probably quite a bit earlier, as argued in the present paper. The two processes seem however not to have reached conclusion until much later: $\langle\mathrm{a}\rangle$ and $\langle\mathrm{O}\rangle$ still co-vary for OE $\bar{a}$ in the late ME period (cf. relevant items in $L A L M E$ ), and $\langle\mathrm{a}>$ for $\mathrm{OE} \overline{a e}$ persists into the later period covered by LAEME. Thus, given that the incipient stages of the GVS have now been dated to c. 1250 , one must conclude that there was in fact an overlap in time between the changes affecting $\bar{x}$ and $\bar{a}$ on the one hand, and the traditional GVS on the other. Hence, the conclusion must be, partly contra Lutz, that the changes to OE $\bar{e}$ should be regarded as part of (rather than a prelude to) any 'great Middle English long-vowel shift', although this apparent difference of opinion may merely reflect a differece in terminology. The same argument applies to the changes to $\mathrm{OE} \bar{a}$, and to $\mathrm{OE} \bar{o}$ north of the Humber. Still, this is not to say that there is a causal relationship between any of these changes, but that they are similar processes which overlap chronologically. The eME changes to the reflexes of $\mathrm{OE} \bar{e} o$ and $\bar{y}$ seem to be simple processes of unrounding and may be different in kind.

Chronologically, the initial stages of the changes to $\bar{c}$ and $\bar{a}$ started before the constituent GVS changes, supporting a push-chain interpretation. The terms 'push-chains' and 'drag-chains' are used here merely as descriptive labels, as they have no explanatory power. Similarly, the changes to long vowels in ME and early ModE may be labelled a 'chain shift' post facto, in so far as the said changes served to uphold phonemic distinctions, but the term does not in itself explain any of the phonetic processes involved. Besides, the concept of a capitalised unitary vowel shift is hardly tenable. Stockwell and Minkova hypothesise (passim) that it was the vocalisation of $\mathrm{OE}\langle\mathrm{g}>$ in $\langle\mathrm{ig} / \overline{\mathrm{i}} \mathrm{g}>$ and $\langle\mathrm{ug} / \overline{\mathrm{u} g}>$ that really set the GVS in motion, in that the two high vowel phonemes /i:/ and /u:/ received diphthongal allophones, which destabilised them and triggered their subsequent phonemic diphthongisation. ${ }^{16}$ The vocalisation of postvocalic $\langle\mathrm{g}>$ is tentatively dated to late OE (Jordan 1925: §87; cf. Jones 1989: 19-21), which in turn suggests a drag-chain scenario.

Interestingly, Samuels (2006) claims to find evidence only of vocalic drag-chains, synchronically as well as diachronically, and she thus denies the existence of push-chains altogether. At some level, such argumentation may be mere theoretical quibble - after all, changes of this kind are often simultaneous and defy easy categorisation. But if it is true that there is empirical evidence only of drag-chains, it appears to reveal something about vowel systems: it is not the danger of merger that triggers chain-shifts, but rather the fact that vowel slots are vacated, creating asymmetries, cf. the principle of 'equal phonetic spacing' (Luick 1932; Martinet 1955; Liljencrants \& Lindblom 1972).

As for the relationship between the changes reported here and other long-vowel changes in the early ME period, the following may be concluded. First, most if not all long-vowel changes

\footnotetext{
${ }^{16}$ A different view is proposed by Lass (1988), although he has in fact changed his view of the vowel shift in recent years (personal communication).
} 
taking place between late $\mathrm{OE}$ and $c .1750$ appear to be related, as they overlap temporally. The question of causation in language change is fraught with difficulty, and correlation is not the same as causation. However, when changes affect sounds which are all members of a partsystem, such as that of long monophthongs, and it can be established in hindsight that the changes contributed to upholding this part-system, then the case is stronger for seeing them as related. True causation may never be established, even for ongoing changes. Second, the changes to $\mathrm{OE} \bar{a}$ must be part of the great vowel shift, as they overlap with the early stages of the vowel shift as traditionally conceived. Third, we are looking at a very long period of particularly intensive vowel-shifting. Fourth, these changes instantiate a small number of recurring processes, that is, raising, fronting, and diphthongisation.

In future research, what is needed is more focus on the likely reasons for this tendency in Germanic languages to shift long vowels along these paths. Work on the interplay between qualitative and quantitative vowel changes has much to offer in this regard (Ritt 1994; Britton 2002; Britton \& Williamson 2002): they suggest that MEOSL of short/lax vowels produced long vowels of 'intermediate quality' (compared to the etymologically long vowels), and that they therefore upset the system and caused shifting. Similarly, when articulatory and acoustic examinations have been undertaken of present-day vowel shifts, like the Diphthong Shift in Cockney, Estuary English and Australian English (Wells 1982) and the Northern Cities Shift in American English (Labov 1994; Gordon 2001; McCarthy 2010), they give promising clues as to what exactly is going on in vocalic chain-shifting. Labov (1994: passim) indeed establishes principles of vowel shifting in which acoustic and articulatory factors are seen to interact. There is a distinct possibility that chain-shifts may be explained as simple gestural overshoot or undershoot, possibly in combination with prosodic features or co-articulatory phenomena (e.g. assimilation), especially as previous work (Stenbrenden 2016) concluded that that most of the long-vowel shifts in ME were in fact combinative, i.e. they started in certain phonetic contexts and then spread through the lexicon.

\section{Conclusions}

This paper has concluded that although use of $\langle\mathfrak{x}\rangle$ was gradually discontinued after 1066, it persisted in some cases into the early fourteenth century, although its frequency dropped substantially after 1200. It has been argued that this marked decrease was the result of changes in pronunciation, that is, vowel raising, which happened in two or more stages.

Moreover, the reflexes of the two $\mathrm{OE} \bar{e}$ 's are not kept apart orthographically in any systematic fashion in any ME dialects: $\langle\mathrm{e}(\mathrm{e})\rangle$ is the dominant spelling everywhere, which indicates that the raising process had begun very early, as indeed all the major textbooks on ME claim.

Additionally, the proportion of $\langle\mathrm{a} / æ / \mathrm{ea}\rangle$ is higher in the early part of the period covered by $L A E M E$ than in the later part, which suggests that the raising process continued throughout the period for the reflexes of both $\bar{e}$ 's, and the orthography eventually followed suit. It also indicates that as $\langle\mathfrak{x}\rangle$ fell out of use, the scribes resorted to other orthographic means of keeping the reflexes of $\mathrm{OE} \bar{e}, \bar{e}^{1}$ and $\bar{e}^{2}$ apart, though not always successfully. In this respect, West Midlands sources stand out with a very high proportion of innovative <ea > for $\bar{e}^{-1}$, especially in the earliest period. <ea> is also used for $\bar{e}^{2}$, but not nearly to the same degree; in the later period, things are more even.

The proposed East Saxon retraction of $\bar{e}^{2}$ to [a:] is supported by the spelling evidence from $L A E M E$, but only for Essex. However, as <a> is almost as frequent for $\bar{e}^{l}$ as for $\bar{e}^{2}$ in Essex, it 
seems that the reflex of $\bar{e}^{l}$ joined in this retraction, which is not at all improbable, given that both would have been $\mathrm{OE}$ [æ:].

Even if the same types of spellings are used for both $\bar{e}$ 's, their proportions vary, and the differences appear to be statistically significant. The evidence thus indicates that there may have been a phonetic difference between $\bar{e}^{1}$ and $\bar{e}^{2}$ in West-Saxon as well as in the other dialects, which goes counter to what is usually claimed. If so, the reflex of $\bar{e}^{1}$ seems to have had an opener quality than that of $\bar{e}^{2}$, because there are more $\langle\mathrm{a} / \mathfrak{a} / \mathrm{ea}\rangle$ for the former and more $\langle\mathrm{e}(\mathrm{e})\rangle$ for the latter. Potential influence from the late West-Saxon standard language should not be overlooked, but such influence seems to be ruled out in the case of The Ormulum: Orm's different use of $\langle\mathrm{a}\rangle$ vs. $\langle\mathfrak{x}\rangle$ vs. $\langle\mathrm{e}\rangle$ for the two $\bar{e}$ 's is statistically highly significant, and surprisingly - points to a closer quality for $\bar{e}^{l}$.

In the future, close analysis of all or some of the scribal profiles in LAEME should be carried out, both in terms of the proportions of co-variants and orthographic systems, and in terms of statistical significance. In such a study, the spellings of the two $\bar{e}$ 's ought to be compared to those of etymological OE $\bar{e}$, with which non-WS $\bar{e}<\bar{e}^{2}$ is supposed to have merged; late OE sources might fruitfully be included.

Finally, it has been shown in this paper that the sound-changes which affected the two $\bar{e}$ 's took some time to reach completion, and that they overlapped in time with the early stages of the great vowel shift. I therefore argue that they must be seen as part of the vowel shift, rather than as similar but unrelated changes.

\section{Appendix}

Table 3. LAEME spellings for $\mathrm{OE} \overline{\boldsymbol{e}}^{1}$ and $\mathrm{OE} \overline{\boldsymbol{e}}^{2}$, by area and date

\begin{tabular}{|c|c|c|c|c|c|c|}
\hline & \multicolumn{3}{|c|}{$\bar{a}^{I}<$ WGmc $a i+i$} & \multicolumn{3}{|c|}{$\overline{\boldsymbol{e}}^{2}<$ WGmc $\overline{\boldsymbol{a}}$} \\
\hline Area & no. & $\%$ & $\langle\mathbf{a} / \mathfrak{a} / \mathbf{e a}\rangle$ & no. & $\%$ & $\langle\mathbf{a} / \mathfrak{a} / \mathbf{e a}\rangle$ \\
\hline \multirow{4}{*}{ NORTH } & $1\langle a\rangle$ & 0.76 & $0.76 \%$ & $9\langle a\rangle$ & 7.63 & $7.63 \%$ \\
\hline & $119<\mathrm{e}>$ & 90.15 & & $107\langle\mathrm{e}\rangle$ & 90.68 & \\
\hline & $12<$ ai/ei $>$ & 9.09 & & $2<$ ai/ei $>$ & 1.69 & \\
\hline & \multicolumn{3}{|c|}{ Total: 132 tokens } & \multicolumn{3}{|c|}{ Total: 118 tokens } \\
\hline \multirow{5}{*}{$\begin{array}{l}\text { East Midlands } \\
1150-1250\end{array}$} & $51<a>$ & 17.83 & \multirow{4}{*}{$\begin{array}{l}\langle\mathrm{a} / æ / \mathrm{ea}\rangle \\
78 \\
27.27 \%\end{array}$} & $65<a>$ & 35.91 & \multirow{3}{*}{$\begin{array}{l}<\mathrm{a} / æ / \mathrm{ea}> \\
98 \\
54.14 \%\end{array}$} \\
\hline & $25<æ>$ & 8.74 & & $33<æ>$ & 18.23 & \\
\hline & $2\langle$ ea $\rangle$ & 0.7 & & $82\langle\mathrm{e}\rangle$ & 45.3 & \\
\hline & $208<\mathrm{e}\rangle$ & 72.73 & & $1<\mathrm{ai}>$ & 0.55 & \\
\hline & \multicolumn{3}{|c|}{ Total: 286 tokens } & \multicolumn{3}{|c|}{ Total: 181 tokens } \\
\hline \multirow{5}{*}{$\begin{array}{l}\text { East Midlands } \\
1250-1350\end{array}$} & $1<\mathfrak{x}>$ & 1.04 & $1.04 \%$ & $4<a>$ & 2.76 & $2.76 \%$ \\
\hline & $93\langle\mathrm{e}\rangle$ & 96.88 & & $140<\mathrm{e}>$ & 96.55 & \\
\hline & $1<\mathrm{ei}\rangle$ & 1.04 & & $1\langle 0\rangle$ & 0.69 & \\
\hline & $1<y>$ & 1.04 & & & & \\
\hline & \multicolumn{3}{|c|}{ Total: 96 tokens } & \multicolumn{3}{|c|}{ Total: 145 tokens } \\
\hline \multirow{5}{*}{$\begin{array}{l}\text { EAST MIDLANDS } \\
\text { TOTAL }\end{array}$} & $51\langle a\rangle$ & 13.35 & \multirow{4}{*}{$\begin{array}{l}<\mathrm{a} / \mathfrak{x} / \mathrm{ea}> \\
79 \\
20.68 \%\end{array}$} & $69\langle a\rangle$ & 21.17 & \multirow{3}{*}{$\begin{array}{l}\mathrm{a} / \mathfrak{x}\rangle \\
10231.29 \%\end{array}$} \\
\hline & $26<\mathfrak{}>$ & 6.81 & & $33\langle\mathfrak{x}>$ & 10.12 & \\
\hline & $2<e a>$ & 0.52 & & $222\langle\mathrm{e}\rangle$ & 68.09 & \\
\hline & $301\langle e\rangle$ & 78.8 & & $1<\mathrm{ai}>$ & 0.31 & \\
\hline & $1<\mathrm{ei}>$ & 0.26 & & $1<0>$ & 0.31 & \\
\hline
\end{tabular}




\begin{tabular}{|c|c|c|c|c|c|c|}
\hline & $1\langle y\rangle$ & 0.26 & & & & \\
\hline & \multicolumn{3}{|c|}{ Total: 382 tokens } & \multicolumn{3}{|c|}{ Total: 326 tokens } \\
\hline \multirow[t]{4}{*}{ SOUTH-WEST } & $1<a>$ & 20 & \multirow{2}{*}{$\begin{array}{l}\langle\mathrm{a} / \mathfrak{x}> \\
360 \% \\
\end{array}$} & $1\langle\mathfrak{x}\rangle$ & 16.67 & $16.67 \%$ \\
\hline & $2\langle\mathfrak{x}\rangle$ & 40 & & $5<e>$ & 83.33 & \\
\hline & $2<e>$ & 40 & & & & \\
\hline & \multicolumn{3}{|c|}{ Total: 5 tokens } & \multicolumn{3}{|c|}{ Total: 6 tokens } \\
\hline \multirow[t]{4}{*}{ SOUTH-EAST } & $1<a>$ & 1.75 & \multirow{4}{*}{$\begin{array}{l}\langle\mathrm{a} / \mathfrak{x}\rangle \\
35.26 \% \\
\end{array}$} & $2\langle a\rangle$ & 2.94 & $2.94 \%$ \\
\hline & $2\langle\mathfrak{x}\rangle$ & 3.51 & & & & \\
\hline & $54\langle e\rangle$ & 94.74 & & $66<e>$ & 97.06 & \\
\hline & \multicolumn{2}{|c|}{ Total: 57 tokens } & & \multicolumn{3}{|c|}{ Total: 68 tokens } \\
\hline \multirow{8}{*}{$\begin{array}{l}\text { West Midlands } \\
1150-1250\end{array}$} & $1<a>$ & 0.26 & \multirow{4}{*}{$\begin{array}{l}<\mathrm{a} / æ / \mathrm{ea}> \\
178 \\
46.96 \%\end{array}$} & $1\langle a\rangle$ & 0.2 & \multirow{3}{*}{$\begin{array}{l}<\mathrm{a} / æ / \mathrm{ea}> \\
55 \\
11.07 \%\end{array}$} \\
\hline & $21\langle æ>$ & 5.54 & & $17\langle\mathfrak{}>$ & 3.42 & \\
\hline & $156<$ ea $>$ & 41.16 & & $37\langle$ ea $>$ & 7.45 & \\
\hline & $200<e>$ & 52.77 & & $424\langle\mathrm{e}\rangle$ & 85.31 & \\
\hline & $1<\mathrm{ei}\rangle$ & 0.26 & & $14<\mathrm{eo}>$ & 2.82 & \\
\hline & & & & $3<$ ai/ei> & 0.6 & \\
\hline & & & & $1\langle\mathrm{ia}\rangle$ & 0.2 & \\
\hline & \multicolumn{3}{|c|}{ Total: 379 tokens } & \multicolumn{3}{|c|}{ Total: 497 tokens } \\
\hline \multirow{8}{*}{$\begin{array}{l}\text { West Midlands } \\
1250-1350\end{array}$} & $5<a>$ & 1.29 & \multirow{3}{*}{$\begin{array}{l}<\mathrm{a} / æ / \mathrm{ea}> \\
69 \\
17.83 \% \\
\end{array}$} & $10<a>$ & 2.05 & \multirow{3}{*}{$\begin{array}{l}<\mathrm{a} / æ / \mathrm{ea}> \\
89 \\
18.27 \%\end{array}$} \\
\hline & $43<\mathfrak{x}>$ & 11.11 & & $40<æ>$ & 8.21 & \\
\hline & $21<$ ea $>$ & 5.43 & & $39<$ ea $>$ & 8.01 & \\
\hline & $313<\mathrm{e}>$ & 80.88 & & $391\langle\mathrm{e}\rangle$ & 80.29 & \\
\hline & $3\langle\mathrm{eo}\rangle$ & 0.77 & & $3\langle\mathrm{eo}\rangle$ & 0.62 & \\
\hline & $2<\mathfrak{i}$ i/ei $>$ & 0.52 & & $2<\mathrm{ei}>$ & 0.41 & \\
\hline & & & & $2\langle i\rangle$ & 0.41 & \\
\hline & \multicolumn{3}{|c|}{ Total: 387 tokens } & \multicolumn{3}{|c|}{ Total: 487 tokens } \\
\hline \multirow{10}{*}{$\begin{array}{l}\text { WEST MIDLANDS } \\
\text { TOTAL }\end{array}$} & $6<a>$ & 0.78 & \multirow{3}{*}{$\begin{array}{l}\langle\mathrm{a} / \mathfrak{x} / \mathrm{ea}> \\
247 \\
32.25 \% \\
\end{array}$} & $11<a>$ & 1.12 & \multirow{3}{*}{$\begin{array}{l}<\mathrm{a} / \mathfrak{\text { ea }}> \\
144 \\
14.63 \%\end{array}$} \\
\hline & $64\langle\mathfrak{x}$ & 8.36 & & $57\langle\mathfrak{x}\rangle$ & 5.79 & \\
\hline & $177<$ ea> & 23.11 & & $76\langle$ ea $>$ & 7.72 & \\
\hline & $513\langle\mathrm{e}\rangle$ & 66.97 & & $815<\mathrm{e}\rangle$ & 82.83 & \\
\hline & $3\langle\mathrm{eo}\rangle$ & 0.39 & & $17\langle$ eo $>$ & 1.73 & \\
\hline & $3<æ i / e i>$ & 0.39 & & $5<$ ai/ei $>$ & 0.51 & \\
\hline & & & & $2\langle i\rangle$ & 0.2 & \\
\hline & & & & $1\langle\mathrm{ia}\rangle$ & 0.1 & \\
\hline & \multicolumn{3}{|c|}{ Total: 766 tokens } & \multicolumn{3}{|c|}{ Total: 984 tokens } \\
\hline & \multicolumn{3}{|c|}{ Total: 1342 tokens } & \multicolumn{3}{|c|}{ Total: 1502 tokens } \\
\hline
\end{tabular}

Table 4. LAEME spellings for OE $\overline{\boldsymbol{e}}^{1}$ and $\mathrm{OE} \overline{\boldsymbol{e}}^{2}$, by county

\begin{tabular}{|c|c|c|}
\hline Area & $\overline{a e^{l}<W G m c ~} a i+i$ & $\bar{a}^{2}<$ WGmc $\bar{a}$ \\
\hline \multicolumn{3}{|l|}{ North } \\
\hline Durham & $3 \mathrm{e}$ & $1 \mathrm{a}, 2 \mathrm{e}$ \\
\hline East Riding, Yks & $1 \mathrm{a}, 28 \mathrm{e}, 1$ ee, 1 ai & $4 \mathrm{a}, 27 \mathrm{e}, 1 \mathrm{ai}$ \\
\hline Lancashire & & $4 \mathrm{e}$ \\
\hline North Riding, Yks & 50 e, 2 ay & $4 \mathrm{a}, 27 \mathrm{e}, 1$ ee, 1 ay \\
\hline West Riding, Yks & 9 e, 3 ee, 1 ei & $23 \mathrm{e}$ \\
\hline York & 24 e, 1 ee, 6 ai, 2 ei & $23 \mathrm{e}$ \\
\hline
\end{tabular}




\begin{tabular}{|c|c|c|}
\hline Cambridgeshire & $4 \mathrm{e}$ & $1 \mathrm{a}, 2 \mathrm{e}$ \\
\hline Ely & $3 \mathrm{e}$ & $11 \mathrm{e}$ \\
\hline Essex & $51 \mathrm{a}, 7 \mathfrak{x}, 2$ ea, $43 \mathrm{e}$ & 65 a, $21 æ, 20$ e \\
\hline Leicestershire & & $1 \mathrm{e}$ \\
\hline Lincolnshire & 6 æ, $44 \mathrm{e}, 1 \mathrm{y}$ & $11 \mathfrak{1}, 21$ e, 1 é \\
\hline Norfolk & $1 \mathfrak{x}, 59$ e, 1 ee, 1 ei & 3 a, 100 e, 5 ee, 10 \\
\hline Northamptonshire & $4 \mathrm{e}$ & $8 \mathrm{e}$ \\
\hline Peterborough & $5 æ, 1 \mathrm{e}$ & $1 æ, 3 \mathrm{e}$ \\
\hline Suffolk & $7 æ, 142 \mathrm{e}$ & 50 e, 1 ai \\
\hline \multicolumn{3}{|l|}{ South-East } \\
\hline Kent & 2 ae, 50 e, 2 éé & $64 \mathrm{e}$ \\
\hline London & $1 \mathrm{a}$ & \\
\hline Sussex & $1 \mathrm{e}$ & $2 \mathrm{e}$ \\
\hline Surrey & $1 \mathrm{e}$ & $2 \mathrm{a}$ \\
\hline \multicolumn{3}{|l|}{ South-West } \\
\hline Hampshire & $2 æ, 2$ e & $1 æ, 5 \mathrm{e}$ \\
\hline Somerset & $1 \mathrm{a}$ & \\
\hline \multicolumn{3}{|l|}{ West Midlands } \\
\hline Berkshire & $1 \mathrm{a}, 97 \mathrm{e}, 1 \mathrm{eo}$ & $46 \mathrm{e}$ \\
\hline Cheshire & $1 \mathrm{a}, 22 \mathrm{ea}$ & 1 ea, 57 e, 1 eo, 1 ai, 2 ei \\
\hline Gloucestershire & $47 \mathrm{e}, 1$ eo & $1 \mathrm{a}, 74 \mathrm{e}, 4 \mathrm{ee}$ \\
\hline Herefordshire & 16 ea, 77 e, 1 éé & 3 ea, 176 e, 2 é, 1 eo, 1 ei, 1 i \\
\hline Oxfordshire & $58 \mathrm{e}$ & $5 \mathrm{a}, 52 \mathrm{e}$ \\
\hline Shropshire & 97 ea, 18 e, 1 ei & 30 ea, 104 e, 2 é, 13 eo \\
\hline Staffordshire & $1 \mathrm{e}$ & $1 \mathrm{e}$ \\
\hline Wiltshire & 1 a, 8 e, 10 éé, 1 ee, 1 eo & 24 ea, 29 e \\
\hline Worcestershire & $\begin{array}{l}3 \text { a, } 64 \text { æ, } 42 \text { ea, } 182 \text { e, } 8 \\
\text { é(é), } 5 \text { ee, } 2 \text { æi/ei }\end{array}$ & $\begin{array}{l}5 \text { a, } 57 \text { æ, } 18 \text { ea, } 268 \text { e, } 2 \text { eo, } \\
1 \text { æi, } 1 \text { i }\end{array}$ \\
\hline Total & $\begin{array}{l}60 \text { a, } 94 \text { æ, } 179 \text { ea, } 989 \text { e(e), } \\
16 \text { ai/ei, } 3 \text { eo, } 1 \text { y }\end{array}$ & $\begin{array}{l}91 \text { a, } 91 \text { æ, } 76 \text { ea, } 1215 \text { e(e), } \\
8 \text { ai/ei, } 17 \text { eo, } 2 \text { i, } 1 \text { ia, } 1 \text { o }\end{array}$ \\
\hline
\end{tabular}

Table 5. $L A E M E<\mathrm{e}>$ spellings for $\mathrm{OE} \overline{\boldsymbol{e}}^{1}$ in early sources (before AD 1200)

\begin{tabular}{|c|c|c|c|}
\hline County & No. & Date & Words with $\langle\mathrm{e}\rangle$ \\
\hline \multicolumn{4}{|l|}{ E Midlands } \\
\hline Peterborough & 149 & 1154 & HEATHEN \\
\hline Essex & 4 & $1150-99$ & HEAT \\
\hline Essex & 1200 & $1175-99$ & 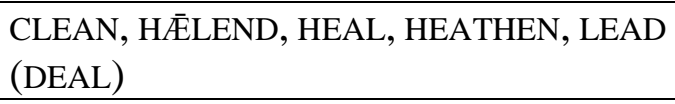 \\
\hline Suffolk & 1300 & $1175-99$ & $\begin{array}{l}\text { CLEAN, HǢEEND, HEAL, HEAT, HEATHEN, } \\
\text { LEAD, SEA, TEACH (DEAL) }\end{array}$ \\
\hline Lincolnshire & 301 & $1175-99$ & CLEAN, LEAD \\
\hline \multicolumn{4}{|l|}{ W Midlands } \\
\hline Worcestershire & 170 & $1175-99$ & HǢEEND \\
\hline Worcestershire & 5 & c. 1200 & HEAT, LEAD, SEA \\
\hline Worcestershire & 2000 & c. 1200 & $\begin{array}{l}\text { CLEAN, HÆ̈EEND, HEAL, HEATHEN, LEAD, } \\
\text { SEA, TEACH (DEAL) }\end{array}$ \\
\hline
\end{tabular}




\begin{tabular}{|l|l|l|l|}
\hline Worcestershire & 2001 & c.1200 & $\begin{array}{l}\text { CLEAN, HǢELEND, HEAL, HEATHEN, LEAD, } \\
\text { SEA, TEACH }\end{array}$ \\
\hline Oxfordshire & 232 & $1175-1224$ & LEAD \\
\hline Worcestershire & $\begin{array}{l}1900 \\
(171-173)\end{array}$ & $1200-49$ & CLEAN, HǢELEND, LEAD, TEACH, WHEAT \\
\hline
\end{tabular}

Table 6. Incidence of <ai/ay>, <æi>, <ei> for OE $\bar{a}^{1}$ and OE $\bar{a}^{2}$ in LAEME

\begin{tabular}{|c|c|c|c|c|c|}
\hline Area & No. & Date & $\begin{array}{l}\bar{a}^{1}<W G m c \\
a i+i\end{array}$ & $\overline{\bar{e}^{2}<\text { WGmc } \bar{a}}$ & Lexemes \\
\hline West Riding, Yks & 295 & $1300-50$ & 8 e, 3 ee, 1 ei & $19 \mathrm{e}$ & ei HEAT \\
\hline York & 296 & $1300-50$ & $\begin{array}{l}24 \text { e, } 1 \text { ee, } 6 \text { ai, } \\
2 \text { ei }\end{array}$ & $23 \mathrm{e}$ & $\begin{array}{l}\text { ai HEATHEN; } \\
\text { ei SEA }\end{array}$ \\
\hline East Riding, Yks & 297 & $1300-50$ & $\begin{array}{l}1 \text { a, } 27 \text { e, } 1 \text { ee, } 1 \\
\text { ai }\end{array}$ & 4 a, 27 e, 1 ai & $\begin{array}{l}\text { ai HǢELU; } \\
\text { HAIR }\end{array}$ \\
\hline $\begin{array}{l}\text { North Riding, } \\
\text { Yks }\end{array}$ & 298 & $1300-50$ & $50 \mathrm{e}, 2$ ay & $\begin{array}{l}4 \text { a, } 27 \text { e, } 1 \text { ee, } 1 \\
\text { ay }\end{array}$ & $\begin{array}{l}\text { ay HEATHEN; } \\
\text { a/ay HAIR }\end{array}$ \\
\hline Suffolk & 1300 & $1175-99$ & 7 æ, $142 \mathrm{e}$ & $50 \mathrm{e}, 1$ ai & ai HAIR \\
\hline Norfolk & 285 & $1300-24$ & 31 e, 1 ei & 3 a, 33 e, 1 o & ei SEA \\
\hline Shropshire & 272 & $1225-49$ & 26 ea, 1 ei & $\begin{array}{l}3 \text { ea, } 57 \text { e, } 2 \text { é, } 2 \\
\text { eo }\end{array}$ & ei HǢELU \\
\hline Cheshire & 118 & $1240-50$ & $1 \mathrm{a}, 17 \mathrm{ea}$ & $\begin{array}{l}1 \text { ea, } 51 \text { e, } 1 \text { eo, } 1 \\
\text { ai, } 2 \text { ei }\end{array}$ & ai/ei HAIR \\
\hline Worcestershire & 278 & $1250-74$ & $\begin{array}{l}1 \text { a, } 24 \text { æ, } 2 \text { ea, } 3 \\
\text { e, } 1 \text { æi }\end{array}$ & $\begin{array}{l}4 \text { a, } 24 \text { æ, } 2 \text { ea, } 1 \\
\text { eæ, } 10 \text { e, } 1 \text { æi, } 1 \text { i }\end{array}$ & $\begin{array}{l}\text { æi LEAD; } \\
\text { R/̄̄D }\end{array}$ \\
\hline Worcestershire & 2 & $1275-99$ & $7 \mathrm{e}, 1 \mathrm{ei}$ & $21 \mathrm{e}$ & ei CLEAN \\
\hline Herefordshire & 246 & $1275-99$ & $10 \mathrm{e}$ & $18 \mathrm{e}, 1 \mathrm{ei}$ & ei R $\overline{Æ D}$ \\
\hline
\end{tabular}

\section{References}

Anderson, Peter (2015), A Structural Atlas of the English Dialects, London and New York: Routledge.

Britton, Derek (2002), 'Northern fronting and the north Lincolnshire merger of the reflexes of ME /u:/ and ME /o:/', Language Sciences, 24, 221-29.

Britton, Derek and Keith Williamson (2002) (ms.), 'A review of Northern Fronting and its developments in England and Scotland', paper read at the $12^{\text {th }}$ ICEHL, Glasgow, Scotland, 23 August 2002.

Campbell, Alistair (1959), Old English Grammar, Oxford: Clarendon Press.

Dobson, Eric (1968), English Pronunciation 1500-1700, Vol. I, 2. ed., Oxford: Clarendon Press. Girard Lomheim, Francine and Chantal Lyche (1991), Phonétique et phonologie du français, Oslo: Universitetsforlaget.

Gordon, Matthew J. (2001), Small-Town Values and Big-City Vowels: a study of the Northern Cities Shift in Michigan, Publication of the American Dialect Society, Number 84, Durham: Duke University Press.

Hogg, Richard (2011), A Grammar of Old English, Volume 1: Phonology, Oxford: Blackwell. Jones, Charles (1989), A History of English Phonology, London: Longman.

Jordan, Richard (1925), Handbuch der mittelenglischen Grammatik: Lautlehre, Heidelberg: Carl Winter Universitätsverlag.

Kitson, Peter (1998), 'Review Article of Kristensson 1995', NOMINA 21, 169-78. 
Kristensson, Gillis (1967), A Survey of Middle English Dialects 1290-1350. The Six Northern Counties and Lincolnshire, Lund: CWK Gleerup.

Kristensson, Gillis (1987), A Survey of Middle English Dialects 1290-1350: the West Midland Counties, Lund: Lund University Press.

Kristensson, Gillis (1995), A Survey of Middle English Dialects 1290-1350: the East Midland Counties, Lund: Lund University Press.

Kristensson, Gillis (1997), 'The Old English Anglian/Saxon boundary revisited', in Jacek Fisiak (ed.), Studies in Middle English Linguistics, Berlin and New York: Mouton de Gruyter, 271-81.

Kristensson, Gillis (2001), A Survey of Middle English Dialects 1290-1350: the Southern Counties. I. Vowels (except Diphthongs), Lund: Lund University Press.

Kristensson, Gillis (2002), A Survey of Middle English Dialects 1290-1350: the Southern Counties. II. Diphthongs and Consonants, Lund: Lund University Press.

Labov, William (1994), Principles of Linguistic Change. Internal Factors, Oxford, UK and Cambridge, USA: Blackwell.

Laing, Margaret (2008), A Linguistic Atlas of Early Middle English, University of Edinburgh. http://www.lel.ed.ac.uk/ihd/laeme2/laeme2.html

Lass, Roger (1988), 'Vowel Shifts, great and otherwise: Remarks on Stockwell and Minkova', in Dieter Kastovsky and Gero Bauer (eds.), Luick Revisited, 395-410, Tübingen: Gunter Narr Verlag.

Lass, Roger and Margaret Laing (2012), "“ea” in Early Middle English: from diphthong to digraph', in David Denison, Ricardo Bermudez-Otero, Chris McCully \& Emma Moore (eds.), Analysing Older English. Studies in English Language, 75-117, Cambridge University Press.

Liljencrants, Johan and Björn Lindblom (1972), 'Numerical Simulation of Vowel Quality Systems: The Role of Perceptual Contrast', Language, 48: 4, 839-862.

Luick, Karl (1914-40), Historische Grammatik der englischen Sprache, Vol. I, Parts 1 \& 2, Oxford: Basil Blackwell.

Luick, Karl (1932), 'Zur neuenglischen Lautgeschichte', Archiv für das Studium der neueren Sprachen, 1932, 89-90.

Lutz, Angela (2004), 'The First Push: a Prelude to the Great Vowel Shift', Anglia, 122: 2, 20924.

Martinet, André (1955), Économie des changements phonétiques: traité de phonologie diachronique, Bern: A. Francke.

McCarthy, Corrine (2010), 'The Northern Cities Shift in Chicago', Journal of English Linguistics XX(X), 1-22.

McIntosh, Angus, Michael Samuels and Michael Benskin (1986), A Linguistic Atlas of Late Mediaeval English, Vols. I-IV, Aberdeen: Aberdeen University Press.

Oxford English Dictionary Online, at http://www.oed.com/

Ringe, Don and Ann Taylor (2014), A Linguistic History of English, Volume 2: The Development of Old English, Oxford: Oxford University Press.

Ritt, Nicolaus (1994), Quantity Adjustment. Vowel lengthening and shortening in early Middle English, Cambridge: Cambridge University Press.

Sievers, Eduard (1968) [translated and revised by Albert Cook], An Old English Grammar, Boston: Ginn.

Samuels, Bridget D. (2006), Nothing to Lose but Their Chains: Rethinking Vocalic Chain Shifting, BA thesis, Harvard University.

Stenbrenden, Gjertrud F. (2010), The Chronology and Regional Spread of Long-Vowel Changes in English, c. 1150-1500, PhD dissertation, University of Oslo. 
Stenbrenden, Gjertrud F. (2016), Long-Vowel Shifts in English, c. 1050-1700: Evidence from spelling, Cambridge: Cambridge University Press.

Stockwell, Robert P. (1985), 'Assessment of alternative explanations of the Middle English phenomenon of high vowel lowering when lengthened in the open syllable', in Roger Eaton et al. (eds.), Papers from the $4^{\text {th }}$ International Conference on English Historical Linguistics, 303-18, Amsterdam, Philadelphia: John Benjamins.

Stockwell, Robert P. and Donka Minkova (1988a), 'The English Vowel Shift: problems of coherence and explanation', in Dieter Kastovsky and Gero Bauer (eds), Luick Revisited, 355-394, Tübingen: Gunter Narr Verlag.

Stockwell, Robert P. and Donka Minkova (1988b), 'A rejoinder to Lass', in Dieter Kastovsky and Gero Bauer (eds), Luick Revisited, 411-17, Tübingen: Gunter Narr Verlag.

Wells, John C. (1982), Accents of English, Cambridge: Cambridge University Press.

Wright, Joseph and Elizabeth M. Wright (1925), Old English Grammar, Oxford: Oxford University Press.

Wright, Joseph and Elizabeth M .Wright (1928), An Elementary Middle English Grammar, Oxford: Oxford University Press.

Wyld, Henry C. (1914), A Short History of English, London: John Murray.

Zachrisson, R.E. (1913), Pronunciation of English Vowels 1400-1700, Göteborg: Wald. Zachrissons Boktryckeri. 